\title{
Quais os significados sobre família em situação de pandemia para os adolescentes?
}

\author{
What are the meanings of families in a pandemic situation \\ for adolescents?
}

Kedma Augusto Martiniano Santos (https://orcid.org/0000-0002-2386-3875) ${ }^{1}$

Paula Orchiucci Miura (https://orcid.org/0000-0002-5103-9787) ${ }^{1}$

Alana Madeiro de Melo Barboza (https://orcid.org/0000-0001-5951-141X) ${ }^{1}$

Cristina Generino dos Santos Lima Araújo (https://orcid.org/0000-0002-6637-1205) ${ }^{1}$

\footnotetext{
${ }^{1}$ Programa de Pós-

\begin{abstract}
This paper aimed to identify and understand the meanings of family in a COVID-19 pandemic situation for adolescents in Northeastern Brazil. This qualitative research used the $D E-T$ Procedure with 32 adolescents from Northeastern Brazil. Thirteen themes were observed, and the most incident were physical distance, expressed feelings, integrating family relationships, technological devices, and disintegrating family relationships. We finalize with the representation of family power in facing the pandemic and family suffering in the face of the public health problem that plagues the country.
\end{abstract}

Key words Adolescents, Family, COVID-19, Pandemic
Resumo Este artigo objetivou identificar e compreender os significados da família em situação de pandemia da COVID-19 para jovens do nordeste brasileiro. Trata-se de uma pesquisa qualitativa, com o uso do Procedimento DE-T. Participaram 32 adolescentes do nordeste brasileiro. Observou-se 13 temas, sendo os mais incidentes: distanciamento físico; sentimentos expressos; relações familiares integradoras; aparelhos tecnológicos; relações familiares desintegradoras. Conclui-se sobre a representação da potência familiar no enfrentamento da pandemia, bem como sobre o sofrimento e padecimento familiar frente ao problema de saúde pública que assola o país.

Palavras-chave Adolescentes, Família, COVID19, Pandemia 


\section{Introdução}

No final de outubro de 2020, o número de casos mundiais com a COVID-19 confirmados equivale a $44.908 .477^{1}$. Desse total, 5.468.270 casos são do Brasil, sendo 1.472.233 da região do Nordeste $^{2}$, equivalente a $26,92 \%$ dos casos no país, o que demonstra a alta incidência nesta região. Diante deste problema de saúde pública vivenciado devido ao novo coronavírus, a população mundial se deparou com diversas medidas de enfrentamento da pandemia ${ }^{3}$. Dentre as medidas adotadas, o distanciamento físico, cujo objetivo visa tentar reduzir a alta transmissibilidade e evitar o esgotamento dos sistemas de saúde por meio da diminuição das interações entre a população, tem se mostrado fundamental para controlar a disseminação do vírus ${ }^{4,5}$.

Em face ao exposto e por conta da alteração na rotina das pessoas, observa-se que a dinâmica familiar, principalmente com crianças e adolescentes, tem demandado maior esforço por parte dos pais/responsáveis ${ }^{6}$. Diante de tais questões, a $\mathrm{UNICEF}^{7}$ elaborou um relatório de orientação sobre o manejo familiar no contexto da pandemia, e apontou para a possibilidade de ansiedade em adolescentes que não possuam ajuda parental. Em consonância com esse relatório, uma revisão da literatura apontou a probabilidade de aumento de estresse ${ }^{8,9}$, ameaça ao bem-estar familiar e de crianças e adolescentes ${ }^{8}$, assim como $\mathrm{o}$ aumento na violência intrafamiliar ${ }^{10-13}$.

Com maior enfoque nos cuidados de proteção e prevenção de contaminação, uma das problemáticas vivenciadas durante uma pandemia é a tendência à negligência de implicações sobre a saúde mental ${ }^{14}$. Compreende-se, assim, a importância e necessidade de contribuições da Psicologia no enfrentamento das repercussões da COVID-1915. Com isso, intervenções psicológicas se mostram de fundamental importância para promoção de saúde mental, diminuição de implicações negativas no desenvolvimento e contribuição no processo de readaptação, maneiras de lidar com as perdas e com as transformações das pessoas após a pandemia ${ }^{15}$.

Polanczyk ${ }^{16}$ aponta que as consequências do isolamento social sobre a saúde mental, inclusive de crianças e adolescentes, podem representar uma "segunda onda" da pandemia. Diante disso, faz-se importante desenvolver reflexões acerca da adolescência e família no período da pandemia, visto que, para além da readaptação por conta do confinamento, jovens encaram a necessidade de uma nova adaptação à realidade naturalmente presente no período da adolescência.
Este artigo, fruto de uma pesquisa com jovens, justifica-se por possibilitar um espaço potencial de experiências subjetivas mutativas na busca por compreender a visão dos jovens sobre a família e suas vivências durante o período de pandemia da COVID-19. Assim, a relevância social deste trabalho está na possibilidade de disponibilizar um espaço de expressão, comunicação e de participação ativa com adolescentes durante o período de pandemia e isolamento físico. Como relevância acadêmica, aponta-se a importância de desenvolver pesquisas com jovens, acerca de suas concepções sobre família durante o período de pandemia da COVID-19, por meio de instrumentos de pesquisa utilizados de forma remota. Diante do exposto, este trabalho teve como objetivo identificar e compreender os significados sobre família em situação de pandemia da COVID-19 para os jovens do Nordeste brasileiro.

\section{Método}

\section{Aspectos éticos}

Este projeto foi aprovado pelo Comitê de Éti$\mathrm{ca}(\mathrm{CEP})$ da Universidade Federal de Alagoas ( $\mathrm{Pa}$ recer: 4.090.450 - CAAE: 31838420.9.0000.5013). Os adolescentes participantes da pesquisa preencheram de forma online o Termo de Assentimento Livre e Esclarecido (TALE), bem como seus pais/responsáveis o Termo de Consentimento Livre e Esclarecido (TCLE). Apenas após o consentimento do responsável e o assentimento do adolescente, por meio de chamada de vídeo, foi realizada a presente pesquisa. Todos os preceitos éticos recomendados pelo Conselho Nacional de Saúde (CNS), conforme resolução no 510/2016 ${ }^{17}$, foram atendidos.

\section{Tipo de estudo}

Trata-se de uma pesquisa qualitativa, descritiva e exploratória. A pesquisa qualitativa caracteriza-se por constituir uma abordagem de cunho interpretativo do mundo, o que implica na inserção do pesquisador nos cenários naturais do fenômeno estudado, objetivando entender e compreender os significados atribuídos pelas pessoas a determinados fenômenos ${ }^{18}$. Uma pesquisa qualitativa com enfoque exploratório propicia ao pesquisador familiarizar-se com o fenômeno, ou seja, com as pessoas e as suas demandas. E uma pesquisa descritiva evidencia "como" e "o que" acerca do fenômeno estudado; através do detalhamento do fenômeno, ela possibilitará 
informações do contexto, que poderão ser usadas de base para pesquisas de cunho compreensivo ${ }^{19}$.

\section{Cenário de estudo e fonte de dados}

Toda pesquisa foi realizada de forma online, em face da situação mundial sobre a pandemia (COVID-19), atendendo a Lei no 13.979 , promulgada em fevereiro de 2020, que se refere às medidas de enfrentamento: quarentena, distanciamento social, fechamento de instituições de ensino, entre outras ${ }^{20}$.

Para compreensão do significado da família em situação de pandemia do coronavírus entre os adolescentes, participaram da pesquisa 32 jovens da região Nordeste do Brasil, sendo estes de ambos os sexos, com idade entre 12 e 17 anos e 11 meses. A amostra constituiu-se por meio da metodologia bola de neve (snowball sampling), uma amostra não probabilística, porém útil para grupos com difícil acesso, sendo constituída por encontrar sujeitos condizentes à população-alvo. Estes sujeitos são denominados de sementes da amostra, pois dão origem aos demais participantes. Posteriormente, a semente auxilia o pesquisador a obter mais contatos com as características requeridas pela pesquisa, seguidamente os indicados pela semente indicam novos participantes e assim sucessivamente ${ }^{21}$.

\section{Coleta e organização de dados}

Em busca da semente da amostra ${ }^{21}$, três adolescentes conhecidos da pesquisadora foram convidados a participar. $\mathrm{O}$ convite da pesquisa foi compartilhado nos grupos de WhatsApp da pesquisadora, solicitando assim, à sua rede de amigos, auxílio no compartilhamento e divulgação da pesquisa em suas redes sociais, buscando um maior alcance de divulgação. O convite da pesquisa possuía as seguintes informações: nome da pesquisadora e orientadora; título da pesquisa; público-alvo; links do TCLE e TALE; aprovação do projeto pelo Comitê de Ética com o CAAE e contatos da pesquisadora.

O contato inicial com os participantes se deu por meio do preenchimento do TCLE e/ou TALE online por parte do adolescente e/ou responsável, o qual possibilitava o acesso da pesquisadora ao termo preenchido, contendo o contato do participante e/ou responsável. $\mathrm{Na}$ sequência a pesquisadora entrava em contato, através de mensagem (Whats $A p p$ ) e estabelecia uma primeira conversa com os interessados que compreendia de: apresentação da pesquisadora; boas-vindas ao parti- cipante (ou ao seu responsável); abertura de um espaço para elucidação de possíveis dúvidas; confirmação de interesse em participar da pesquisa; agendamento do dia e horário para a chamada de vídeo conforme disponibilidade do participante; solicitação do preenchimento de um dos termos faltante (TCLE ou TALE), visto que muitos dispunham de apenas um termo preenchido. Por fim, a pesquisadora informava ao participante ou responsável que entraria em contato um dia antes do agendado para confirmar a realização da pesquisa e se colocava à disposição caso desejassem contatá-la. Através desse segundo contato com o participante, por meio de mensagem, a maioria dos adolescentes confirmou presença e compareceu no horário marcado. Alguns pediram para remarcar, e assim foi feito.

A realização da coleta se deu através de uma chamada de vídeo pelo Messenger. A pesquisadora enviava o link da sala onde encontraria o participante, quando o participante não dispunha do aplicativo (Messenger), a chamada de vídeo era feita diretamente pelo WhatsApp. Neste encontro individual e virtual, a pesquisadora inicialmente estabelecia rapport com o adolescente (conversa informal e questionamento quanto a possíveis dúvidas por parte do jovem referente a pesquisa), e depois aplicava dois instrumentos: questionário sociodemográfico e Procedimento Desenho -Estória Temáticos ${ }^{22,23}$.

O questionário sociodemográfico foi lido e preenchido pela pesquisadora, e este foi composto por: iniciais do nome, idade, sexo, cor, escolaridade, repetência, rede escolar (pública ou particular), aulas online ( $\operatorname{sim} /$ não/outros), atividade laboral e direitos garantidos ( $\operatorname{sim} /$ não), estado civil, com quem reside, cidade/estado.

O Procedimento de Desenho-Estória com Tema (PDE-T) é uma derivação do Procedimento de Desenho-Estória (DE), elaborado por Walter Trinca. O DE foi desenvolvido como uma técnica clínica de investigação da personalidade e foi pensado a partir da possibilidade de construção "entre" sujeitos. Como base para essa proposta, Trinca ${ }^{24}$ utilizou a ideia de Jogo do Rabisco proposta por Winnicott ${ }^{25}$. Nesse jogo, Winnicott propõe uma relação entre inconscientes e possibilita uma forma de intervenção a partir da comunicação baseada na subjetivação do desenho.

Assim sendo, o PDE-T, desenvolvido por Aiello-Vaisberg ${ }^{26}$, configura-se como uma variante do Procedimento DE de Walter Trinca ${ }^{27}$ e também é considerado uma estratégia investigativa psicológica que tem como base a teoria de Winnicott. Ressalta-se que, essa é uma técnica psica- 
naliticamente orientada, com vistas a facilitar a comunicação emocional levando em conta um contexto intersubjetivo, com um caráter sempre interpretativo, compreensivo e de "intervenções transicionais" ${ }^{28}$ (p.282), pautado na possibilidade do gesto espontâneo e baseando-se na postura criativa e integradora que ocorre nesse encontro inter-humano entre paciente e terapeuta ${ }^{29}$.

O PDE-T constitui-se por pedir ao sujeito a produção de um desenho com um tema específico, seguidamente é solicitado que este conte uma história sobre o que desenhou e atribua um título. O PDE-T objetiva promover a elaboração das experiências do sujeito ao tema proposto, através de articulações simbólicas, e permite uma investigação quanto às angústias e defesas do examinando, devido às instruções que direcionam um tema específico ${ }^{22}$. O referido procedimento não objetiva um psicodiagnóstico abrangente, conquanto beneficia a compreensão de como um sujeito ou um grupo dá significados a um tema ${ }^{30}$.

Aos adolescentes foi solicitado um desenho com a seguinte consigna, "desenhe uma família em situação de pandemia do coronavírus (COVID-19)". Após o término do desenho, pedia-se para o adolescente registrar uma história concernente ao desenho no verso da folha, e dar um título para a unidade de produção. Ao jovem era solicitado que mostrasse o desenho para a pesquisadora, e depois lesse a história e o título criado. Posteriormente, o adolescente fotografava e enviava a unidade de produção para a pesquisadora, para ser analisada.

\section{Análise de dados}

O procedimento Desenho-Estória Temático (PDE-T) foi analisado segundo Trinca ${ }^{27}$, que recomenda a análise das expressões gráficas e verbais de forma conjunta, considerando a complementaridade do desenho e da história. Para a identificação dos temas no material, realizou-se o procedimento da análise de conteúdo de $\operatorname{Bardin}^{30}$, que consistiu em três etapas: pré-análise; exploração do material; e tratamento dos resultados. Quanto à primeira fase, esta implicou na leitura flutuante do material coletado na pesquisa, objetivando a constituição de indicadores. $\mathrm{Na}$ fase seguinte, o material foi explorado, desenvolvida a codificação (seleção de temas recorrente) e categorização do material coletado (agrupamento de temas ressurgentes). E posteriormente, na terceira fase - tratamento dos resultados - ocorrendo a interpretação dos resultados obtidos. Nessa fase utilizou-se referencial psicanalítico winnicottia- no, bem como pesquisas atuais sobre a temática. Com intuito de realizar uma análise mais imparcial e fidedigna, esta foi desenvolvida de forma individual por duas juízas, e nos casos que houve discordância entre as juízas quanto aos temas dos desenhos e/ou histórias, solicitou-se a avaliação de uma terceira juíza.

\section{Resultados e discussão}

Através do questionário sociodemográfico foi possível identificar o perfil dos 32 adolescentes participantes (Tabela 1).

A Tabela 1 aponta que a amostra foi constituída por 32 adolescentes de ambos os sexos, sendo 24 do sexo feminino e 8 do sexo masculino. A média da idade dos participantes foi de 14,5. A idade mínima e máxima para ambos os sexos foi de 12 e 17 anos. Quanto a cor dos participantes (ambos os sexos), 16 (50\%) eram pardos, $10(31,25 \%)$ brancos e $6(18,75 \%)$ pretos. E sobre a escolaridade, $17(53,12 \%)$ adolescentes cursavam o fundamental II, $14(43,75 \%)$ adolescentes estavam no ensino médio incompleto, e apenas um $(3,12 \%)$ adolescente com ensino médio completo.

De acordo com a análise estatística mais atual do IBGE $^{31}$, os estados do Nordeste compõem cerca de 53 milhões de habitantes, sendo essa população composta por $62,5 \%$ de pardos, $29,2 \%$ de brancos, 7,8\% de pretos, e $0,5 \%$ de indígenas. Diante disso, é visível que, apesar de ser um número restrito de participantes nordestinos, os dados sociodemográficos levantados acerca da etnia dos participantes dessa pesquisa estão em consonância com a análise do IBGE, o que reafirma a representatividade, principalmente, de pardos nesta região.

Para além das informações sociodemográficas, também foram analisados os temas dos desenhos-estória com tema (DE-T). Aqui, foi possível identificar 16 temas (Tabela 2). Ressalta-se que em um DE podem ter sido identificadas mais de uma temática.

Observa-se que as temáticas com maiores incidências foram: distanciamento físico, sentimentos expressos e relações familiares integradoras. E as temáticas com menos aparições (somente uma aparição) foram três: desigualdade social, auxílio governamental e projetos de vida. Estas e as demais temáticas serão abordadas com maior aprofundamento a seguir.

O tema Sentimentos Expressos, que compreende os sentimentos comunicados pelos jovens em seus DETs, teve 25 aparições. Desse total, ca- 
Tabela 1. Dados sociodemográficos dos participantes da pesquisa. Categorização da amostra $(n=32)$.

\begin{tabular}{llrrr}
\hline \multicolumn{1}{c}{ Variável sociodemográfica (contínua) } & \multicolumn{1}{c}{ M } & DP & Mínimo & Máximo \\
\hline Idade (anos) & 14.50 & 2.50 & 12 & 17 \\
\hline \multicolumn{1}{c}{ Variáveis sociodemográficas (categorias) } & & & $\mathbf{n}$ & $\%$ \\
\hline Sexo & Feminino & & 24 & 75 \\
& Masculino & 8 & 25 \\
Cor & Preto & 6 & 18,75 \\
& Pardo & 16 & 50 \\
Escolaridade & Branco & 10 & 31,25 \\
& Fundamental II & 17 & 53,12 \\
& Ensino médio incompleto & 14 & 43,75 \\
& Ensino médio completo & 1 & 3,12 \\
\hline
\end{tabular}

Fonte: Autoras, 2020.

Tabela 2. Temas do Procedimento Desenho-Estória com tema (PDE-T) dos adolescentes da região Nordeste do Brasil.

\begin{tabular}{lc}
\hline \multicolumn{1}{c}{ Temas } & Total \\
\hline Distanciamento físico & 26 \\
Sentimentos Expressos & 25 \\
Relações familiares integradoras & 22 \\
Aparelhos tecnológicos & 13 \\
Relações familiares desintegradoras & 10 \\
Atividade laboral & 11 \\
Alimentação & 7 \\
Prevenção/Proteção & 6 \\
Rotina & 6 \\
Adoecimento & 5 \\
Cuidado & 4 \\
Morte & 2 \\
Animais de estimação & 2 \\
Estudos & 2 \\
Auxílio governamental & 1 \\
Projetos de vida & 1 \\
\hline
\end{tabular}

Fonte: Autoras, 2020.

torze DETs referem-se a sentimentos advindos de ambientes suficientemente bons que, segundo Winnicott $\mathrm{t}^{32}$, dizem respeito a um ambiente que supra as necessidades básicas físicas e emocionais do indivíduo, possibilitando confiabilidade e segurança. Diante disso, observou-se que a união (9) foi o sentimento mais abordado, sendo relacionado a momentos felizes e afetuosos, proteção e cuidado por parte dos familiares, aproximações e reaproximações; seguindo de sentimentos de superação/união (5), referente ao enfrentamento de alguma dificuldade advinda da pandemia da COVID-19 pelos familiares que se mantiveram unidos e superaram o problema.
Diante dos dados supradescritos, é possível considerar a importância dos sentimentos na vivência da situação pandêmica. A difusão do novo coronavírus trouxe consigo a necessidade de refletir sobre o lugar que o outro ocupa, ressaltando-se a empatia, a alteridade e a fraternidade ${ }^{33}$, sentimentos observados nos 24 DETs, tanto de união (felicidade, proteção e cuidado), como de superação de conflitos, sentimentos partilhados em ambientes suficientemente bons, onde a confiabilidade e a segurança no ambiente é possível. Winnicott ${ }^{32}$ reitera que os afetos se constituem como uma condição necessária do aparelho psíquico e tem relação com o desenvolvimento emocional. A saúde do psiquismo humano depende de um ambiente facilitador, circunstância representada pelos adolescentes nos catorze DETs.

Em onze DETs foram observados sentimentos advindos de ambiente insuficientemente bom ou de ausência de ambiente bom. Ressalta-se que, de acordo com a teoria de Winnicott ${ }^{32}$, um ambiente considerado não suficientemente bom pode ocasionar insegurança e desconfiança por parte do indivíduo, o que pode comprometer um desenvolvimento considerado saudável. Em relação a isso, foram observados sentimentos como: (5) solidão devido ausência afetiva de relação familiar; (3) tristeza devido a discussões e desentendimentos familiares; (3) tristeza por outros motivos.

Esses dados corroboram os estudos que apontaram para o aumento de estresse na família diante da pandemia ${ }^{8,9}$, bem como acerca da ameaça ao bem-estar familiar e de crianças e adolescentes neste contexto de isolamento físico $^{8}$. A experiência da pandemia da COVID-19 trouxe à baila a necessidade de refletir acerca da saúde mental, considerando que a atual situação 
pode produzir adoecimento: ansiedade, estresse, depressão, insônia, medo. Não obstante, alguns grupos podem mostrar-se mais propensos em detrimento de perdas ou vulnerabilidade social ${ }^{34}$.

Isso reforça a importância do espaço de escuta, comunicação e expressão que a presente pesquisa proporcionou aos adolescentes ao poderem falar sobre família, sentimentos advindos da situação de pandemia entre outros assuntos que desejassem. Indo ao encontro do que ressaltam alguns pesquisadores ${ }^{15}$ sobre a importância e necessidade de contribuições da Psicologia no enfrentamento das repercussões da COVID-19.

Quanto ao tema Distanciamento Físico, esta apareceu em 26 DETs e refere-se ao cumprimento da quarentena pela família ou parte desta. Vinte e dois DEs trouxeram as famílias em quarentena, tal identificação foi feita através dos desenhos e outros referiram estar em casa através da história. Em quatro DETs retratam parte da família em quarentena, por exemplo; responsáveis indo ao trabalho. Observa-se que a maioria dos jovens representou famílias cumprindo as medidas de enfrentamento da COVID-19 por meio do distanciamento físico. Assim, esta questão dialoga com o cumprimento da medida preventiva da COVID-19 - distanciamento físico -, demarcando que a maioria dos DETs retratam as famílias em situação de quarentena, cumprindo assim a Lei no 13.979 que foi promulgada no Brasil em fevereiro de 2020, a qual demarca medidas de enfrentamento: quarentena, distanciamento físico, fechamento de instituições de ensino, entre outras ${ }^{35}$.

Para além dos cuidados associados ao cumprimento do distanciamento físico, foram observadas outras formas de Prevenção e Proteção em seis DETs, os quais retrataram o uso de máscaras, álcool em gel e/ou higienização (lavar mãos e máscara). Estudos ${ }^{34,36}$ enfatizaram a importância de aperfeiçoar a intenção das pessoas concernentes à prevenção durante a crise e a não propagar a doença, ao demonstrar um cuidado que empodera e ressalta o bem-estar.

Nesta direção do cuidado familiar diante da pandemia da COVID-19, observa-se o tema Cuidado com quatro aparições nos DETs, os quais referiram-se aos cuidados do(s) responsável(s) para com os filhos, ou a família cuidando-se e prevenindo-se.

Percebe-se que a maioria dos cuidados foram oferecidos por parte da família a seus membros, demonstrando relações familiares integradoras. Dias $^{37}$ afirma que um adolescente que conseguiu incorporar o sentido (positivo) de família, experiência a possibilidade de autonomia com uma sensação de segurança, visto que uma relação familiar suficientemente boa inclui, também, confiabilidade e proteção, conforme observado em quatro desenhos nos quais foram representados preocupação e cuidado por parte dos pais para com a prole.

Todas essas temáticas (distanciamento físico, prevenção e proteção, cuidado) convergem com o tema Relações Familiares Integradoras. Aqui, optou-se pelo termo "integradoras" numa associação à teoria de Winnicott ${ }^{38}$, visto que ele aponta como "fatores integradores e desintegradores afetam diretamente a vida familiar"(p.67). Sobre a noção de fatores integradores, Winnicott ${ }^{38}$ discorre que são elementos que contribuem para que os membros familiares vivenciem um relacionamento considerado saudável ao processo de desenvolvimento físico, psíquico e emocional. Assim, as relações familiares integradoras foram identificadas em 22 dos DETs, nos quais, em 13 DETs foram observadas interações (famílias conversando, voltando das compras, divertindo-se) e proximidade familiar (familiares juntos). Em cinco DETs percebeu-se interação familiar por aparatos tecnológicos e/ou alimentar como, por exemplo; assistindo juntos televisão e comendo pipoca/pizza, bem como interagir com família pelas redes sociais; e em quatro DETs abordaram a superação de um conflito devido às dificuldades advindas da pandemia.

De acordo com Winnicott ${ }^{38}$, um ambiente familiar satisfatório possibilita experiências de confiabilidade e continuidade, pontos relevantes para que o adolescente consiga se desenvolver emocionalmente de forma satisfatória, o que ocasiona possibilidades criativas de lidar com tensão, aceitar e tolerar conflitos. Pôde-se observar que os DETs retratam um ambiente familiar de interações prazerosas (assistir, comer, tempo juntos, diálogos), de enfrentamento afetivo diante das dificuldades advindas da pandemia, o que demonstra as potencialidades das relações familiares para esses jovens. $\mathrm{Na}$ adolescência, o ambiente (nesse caso o familiar) tem importante papel no acolhimento e na continuidade de existência do interesse da família pelo adolescente. Isso pode ser evidenciado nos 22 DETs que apontam proximidade entre os familiares, ausência de conflitos, momentos mais espontâneos e afetivos, e mesmo em situações em que os adolescentes apontaram alguns momentos de insegurança e conflito, pois foram superados ${ }^{38}$.

O tema Animais de Estimação refere-se aos animais (gatos) que foram representados em dois DETs como pertencentes à família. Segun- 
do estudo desenvolvido por Giumelli e Santos ${ }^{39}$, os animais foram considerados como membros da família dos entrevistados, e a relação com os animais foi associada à sentimentos de amor e carinho, e a perda destes membros familiares foi referida por sentimentos de tristeza e solidão.

Observa-se que o tema de Relações Familiares Desintegradoras se fez presente em 10 DETs, nos quais foram retratados afastamento dos familiares entre si, não interação, brigas e discussões Ressalta-se que a nomenclatura "desintegradora" foi atribuída pelas autoras embasadas na teoria de Winnicott, o qual define os fatores de desintegração familiar como elementos do ambiente e das relações familiares que afetam/interrompem o desenvolvimento dos membros da família ${ }^{32}$. Em seis DETs foi abordado não interação familiar devido ao excessivo uso das tecnologias, bem como afastamento dos membros familiares. Em quatro DETs foram referidas brigas e discussões: (2) discussões entre adolescente e pais; (1) mãe sobrecarregada com afazeres domésticos e cuidado do filho sem receber apoio do cônjuge; (1) abordou família com problemas pela irresponsabilidade na administração da renda, e uso de bebidas e drogas.

Observa-se com esses dados a representação do impacto da pandemia da COVID-19 nas relações familiares: a morte devido a doença; sobrecarga do trabalho doméstico, aumento de conflitos, brigas e discussões. Como afirmado por Winnicott ${ }^{38}$, "é quando a família se rompe, ou ameaça romper-se, que percebemos o quão importante é a família intacta”(p.133). Diante disso e do que foi representado pelos adolescentes, percebe-se que a instabilidade da relação familiar afeta o ambiente e, consequentemente pode interromper o amadurecimento do indivíduo. Sobre isso, Winnicott ${ }^{40}$ complementa afirmando que, muitas vezes, quando o indivíduo não vivencia um sentimento de segurança no lar, pode procurar fora de casa o que lhe falta, como apresentado em um DET que representaram desentendimentos com saída da adolescente para balada. Nesta direção, Rodrigues e Lins ${ }^{41}$ enfatizam que as práticas parentais são de suma importância, haja vista o papel indispensável dos pais no desenvolvimento dos filhos, uma vez que aspectos ligados à saúde mental podem ser vivenciados de maneira negativa na situação pandêmica, com o desencadeamento de sintomas psíquicos ou a exacerbação deles.

Um outro ponto relevante também observado em alguns dos DETs (com muitos aparelhos tecnológicos) e que converge com o estudo de Dias ${ }^{37}$, é o fato de que muitas famílias possuem recursos (materiais e financeiros), mas tais recursos não são aproveitados para fomentar as relações afetivas, como foi observado nos DETs em que a família possuía diversos aparatos tecnológicos, entretanto, não se relacionam e compartilham experiências, ficando cada um isolado em diferentes cômodos. Esses dados corroboram o trabalho de Thomazini e Goulart ${ }^{42}$, que aponta para o uso de aparatos tecnológicos como interferindo diretamente no funcionamento saudável familiar.

$\mathrm{O}$ tema Aparatos Tecnológicos apareceu em 13 DETs, e em cinco destes aparatos como TV e computador foram utilizados para assistir cultos, lives, filmes. Cinco DETs abordaram sobre o uso de celulares, TVs e computadores, e três DETs referiram ao uso da internet para acessar redes sociais, acompanhar notícias e ouvir músicas. Deste modo, os aparatos mais utilizados nas representações foram TV, computador, celulares, sendo mais utilizados para assistir (filmes, cultos e live), e navegar na internet (redes sociais; notícias). A pandemia resultou em alterações significativas nas atividades laborais e familiares: home office, atividades escolares remotas de crianças e adolescentes, compras, e encontros familiares/amigos foram transpostos para o mundo virtual, todas essas mudanças implicaram no aumento do uso das tecnologias pelas pessoas ${ }^{43}$. A presença do aparato tecnológico nos DETs parece retratar um pouco essas mudanças advindas pela quarentena. O uso de aparatos tecnológicos e afastamento familiar pôde ser observado na temática relações familiares desintegradoras, dados que vão ao encontro do que Thomazini e Goulart ${ }^{42}$ esboçam sobre a tecnologia aproximar as pessoas do acesso às informações a nível mundial, mas afastar aqueles que estão próximos fisicamente.

Por outro lado, apesar das possibilidades de interferências no funcionamento familiar devido o uso das tecnologias na quarentena, muitas pessoas podem utilizar esse tempo para assistirem filmes, ouvir músicas, estudar ou fortalecer os laços familiares, buscando melhora na qualidade de vida no período de distanciamento físico ${ }^{44}$, como apresentados em alguns DETs na temática relações familiares integradoras (assistir filmes, cultos, lives com membros da família, bem como interagir com a família pelas redes sociais). Assim sendo, as tecnologias podem ser utilizadas tanto para distanciamento como para aproximação familiar neste período de pandemia.

Quanto ao tema Atividade Laboral, esta apareceu em 11 procedimentos: (7) saída do responsável familiar para o trabalho, sendo este como 
uma necessidade para o sustento familiar; (2) afazeres domésticos realizados por adolescente e mãe; (1) pais em casa por ser empresário/fazendeiro; (1) redução dos salários dos responsáveis da família. É notório que a maioria das atividades laborais referidas pelos adolescentes configura-se como a saída de responsáveis para o trabalho. Assim, ressalta-se que nem todas as famílias dispõem de recursos financeiros para vivenciarem o distanciamento físico (ex: empresário/fazendeiro em um DET), pois como abordado sete DETs, o trabalho foi caracterizado como necessário para sustento familiar, estes responsáveis não vivenciam o distanciamento físico devido às condições financeiras. A pandemia da COVID-19, com a medida preventiva do distanciamento físico, evidenciou e ampliou vulnerabilidades sociais, e quando associada à instabilidade nas atividades laborais e na renda de algumas famílias (ex. redução de salários em um DET), pode demarcar vulnerabilidades e configurar a saída para o trabalho como uma necessidade ${ }^{45}$. Deste modo, a preservação da saúde destes trabalhadores, que precisam manter-se ativos devido às circunstâncias socioeconômicas, mostra-se fundamental para o controle da disseminação da doença e para a proteção daqueles em situação de quarentena ${ }^{4}$.

Sobre o tema Alimentação, este foi observado em sete procedimentos: (3) desenharam membros familiares à mesa (frutas); (2) comendo (pipoca/pizza e suco) enquanto assistiam TV; (1) familiares voltando das compras (frutas/verduras); (1) diálogo sobre almoço estar pronto. Observase nesta temática que as famílias se organizam, se relacionam, se unem, se comunicam em torno da alimentação, como foi observado em sete DETs. Segundo Viero e Blümke ${ }^{46}$, a alimentação está para além do "manter-se vivo", configurando-se como um fenômeno social, e a sociabilidade em torno da alimentação envolve a partilha do alimento, assim como os vínculos afetivos que podem ser construídos ou reforçados, partilhar as refeições com alguém possibilitam um momento mais agradável, e viabilidade de diálogos.

O tema Rotina refere-se tanto à rotina como a mudança de rotina das famílias em situação de pandemia, e esta apareceu em seis DETs. Quatro dessas mudanças de rotina foram referidas como: (2) positiva para (re)aproximação; (1) adoção de um novo estilo de vida - vida no campo; (1) formação de rotina diária familiar para driblar o tédio (assistir filme). Dois DETs remeteram a mudanças de rotina devido a situação de pandemia, apresentadas de forma saudosista, como afastamento do trabalho, escola, lazer, e congregação religiosa. Desta forma, a maioria dos DETs representou mudança de rotina como: aproximação/ reaproximação familiar, mudança para o campo, e afastamentos (trabalho, escola, lazer, igreja), sendo abordadas de forma saudosista. Lima et al. ${ }^{47}$ enfatizam que a pandemia afetou o cotidiano das pessoas e outras práticas de vida e saúde precisaram ser modificadas, como apresentadas nos DETs.

O tema Adoecimentos configura-se por qualquer adoecimento físico que pode (ou não) ocasionar em morte, e em sua maioria, associados ao COVID-19. A referência especificamente a adoecimentos foi observada em cinco DETs, sendo que quatro destas aparições referiram-se ao adoecimento pela COVID-19. Já em relação aos adoecimentos, o tema Morte foi observado em dois procedimentos, e em ambos as mortes foram em face da COVID-19. Observa-se uma possível relação com a realidade do país vivida por familiares, amigos e acompanhada por meio de noticiários. Até o dia 22 de outubro de 2020, o Brasil apresentou o total de 155.962 óbitos registrados devido à COVID-19, com uma média equivalente a 493 mortes por dia nos últimos sete dias ${ }^{2}$. Especificamente no Nordeste, os dados mostram um total de 41.412 óbitos $^{2}$, o que equivale a $26,55 \%$ dos óbitos no país. Tais dados refletem a importância dos cuidados e do cumprimento da medida de isolamento (sempre que possível), podendo ser a morte uma consequência do adoecimento pela COVID-19.

E sobre o tema Estudos, esta foi abordada em dois DETs: (1) pais preocupados com o arcar do estudo superior dos filhos após a pandemia, visto que, a família não possuía recursos financeiros para tal; (1) estudos em família. Ambos DETs demarcam uma preocupação, suporte e participação dos genitores nos estudos da prole, o que remete às relações familiares integradoras. De acordo com Guidetti ${ }^{48}$, as famílias que oferecem um suporte educativo aos filhos podem propiciar mecanismos para atenuar as desigualdades econômicas e sociais dos alunos quanto ao futuro desempenho escolar.

Dois temas apareceram uma única vez (Projetos de vida e Auxílio governamental). O tema Projetos de Vida referiu-se aos planos profissionais (médica) da adolescente. Deste modo, observa-se que o projeto da adolescente no DET envolve o tema estudos, profissionalização. A capacidade de traçar objetivos, fazer planos para o futuro e ter pessoas em quem confie para compartilhá -los, pode trazer grandes ganhos no percurso de situações delicadas, como a pandemia do coro- 
navírus ${ }^{49}$, fazendo um diálogo com o tema Relações Familiares Integradoras, que possibilitam aos membros familiares uma confiabilidade neste ambiente e então, viabilidade para que o adolescente possa pensar e planejar seu futuro. O tema Auxílio Governamental fez referência ao auxílio emergencial adotado no Brasil e apareceu em um DET. A Lei 13.982/2020 concede o auxílio emergencial ( $\$$ \$ 600) a trabalhadores informais, pessoas de baixa renda e desempregados, como uma medida excepcional de proteção social durante o enfrentamento da COVID-19 ${ }^{20}$.

\section{Considerações finais}

Este artigo identificou e compreendeu os significados sobre família em situação de pandemia da COVID-19 para alguns jovens do Nordeste brasileiro. Observou-se mudanças nas relações familiares representadas pelos participantes da pesquisa, em face à situação de pandemia da COVID-19 que assola o país. Enquanto alguns adolescentes representaram que a pandemia ocasionou um distanciamento afetivo familiar, outros retrataram uma (re)aproximação entre os familiares, com a possibilidade de passar mais tempo com a família, o uso de tecnologias em conjunto e a alimentação como forma de (re)aproximar familiares nesse momento de quarentena. Perce- beu-se também, que a situação de pandemia da COVID-19 ocasionou novas reflexões acerca das noções de cuidado aqui identificado como distanciamento físico, proteção/prevenção, relações familiares de cuidado.

Os adolescentes participantes demonstraram em suas produções tanto sentimentos advindos de ambientes suficientemente bons vinculados a relações familiares integradoras, quanto sentimentos oriundos de ambientes insuficientemente bons associados à relações familiares desintegradoras. As relações integradoras foram mais representadas do que as desintegradoras, o que talvez aponte para a saúde e potência das famílias em lidar com as dificuldades da pandemia, porém observa-se também o sofrimento e o padecimento de famílias frente ao problema de saúde pública da COVID-19 e suas repercussões.

Ressalta-se a potencialidade desta pesquisa ao possibilitar espaço de expressão e comunicação aos adolescentes participantes por meio do PDE-T de forma remota. Como limitação, por se tratar de uma pesquisa remota, só participaram jovens com acesso à internet e com posse de aparatos tecnológicos, não sendo possível qualquer generalização dos dados da presente pesquisa. Além disso, outra limitação observada refere-se a uma não representatividade de todos os estados do Nordeste brasileiro (9), visto que só foram alcançados adolescentes de cinco estados.

\section{Colaboradores}

KAM Santos trabalhou na coleta, tratamentos dos dados, metodologia, concepção, revisão e redação final. PO Miura trabalhou na supervisão da pesquisa e da escrita, análise formal (apoio), e liderou a escrita, revisão e edição. AMM Barboza trabalhou na análise formal (apoio), e na escrita, revisão e edição (igualdade). CGSL Araújo atuou na análise formal (apoio) e na escrita, revisão e edição (apoio). 


\section{Referências}

1. Dong E, Du H, Gardner L. An interactive web-based dashboard to track COVID-19 in real time. Lancet Infect Dis 2020; 20(5):533-534.

2. G1. Mortes e casos de coronavírus nos estados [Internet]. [acessado 2020 jul 20]. Disponível em: https:// especiais.g1.globo.com/bemestar/coronavirus/estados-brasil-mortes-casos-media-movel/.

3. Organização Mundial da Saúde (OMS). Doença de coronavírus 2019 (COVID-19) situação relatório - 78 [Internet]. [acessado 2020 jul 20]. Disponível em: https://www.who.int/docs/default-source/coronaviruse/situation-reports/20200407-sitrep-78-covid-19. pdf?sfvrsn=bc43e1b_2.

4. Fiho JMJ, Assunção AÁ, Algranti E, Garcia EG, Saito CA, Maeno M. A saúde do trabalhador e o enfrentamento da COVID-19. Rev Bras Saude Ocup 2020; 45:e14.

5. Aquino EML, Silveira IH, Pescarini JM, Aquino R, Souza-Filho JA, Rocha AS, Ferreira A, Victor A, Teixeira C, Machado DB, Paixão E, Alves FJO, Pilecco F, Menezes G, Gabrielli L, Leite L, Almeida MCC, Ortelan N, Fernandes QHRF, Ortiz RJF, Palmeira RN, Pinto Junior EP, Aragão E, Souza LEPF, Barral Netto M, Teixeira MG, Barreto ML, Ichihara MY, Lima RTRS. Medidas de distanciamento social no controle da pandemia de COVID-19: potenciais impactos e desafios no Brasil. Cien Saude Colet 2020; 25(Supl. 1):2423-2446.

6. Marques ES, Moraes CL, Hasselmann MH, Deslandes SF, Reichenheim ME. A violência contra mulheres, crianças e adolescentes em tempos de pandemia pela COVID-19: panorama, motivações e formas de enfrentamento. Cad Saude Publica 2020; 36(4):1-6.

7. Fundo das Nações Unidas para a Infância (UNICEF). How teenagers can protect their mental health during COVID-19 [Internet]. [cited 2020 out 12]. Available from: https://www.unicef.org/coronavirus/how-teenagers-can-protect-their-mental-health-during-coronavirus-covid-19.

8. Prime $\mathrm{H}$, Wade M, Browne DT. Risk and resilience in family well-being during the COVID-19 pandemic. Am Psychol 2020; 75(5):631-643.

9. Spinelli M, Lionetti F, Pastore M, Fasolo M. Parents' stress and children's psychological problems in families facing the COVID-19 outbreak in Italy. Front Psychol 2020; 11:1713.

10. Campbell AM. An increasing risk of family violence during the Covid-19 pandemic: Strengthening community collaborations to save lives. Forensic Sci Int 2020; 2:100089.

11. Usher K, Durkin J, Bhullar N. The COVID-19 pandemic and mental health impacts. Int J Ment Health Nurs 2020; 29(3):315-318.

12. Bradbury-Jones C, Isham L. The pandemic paradox: the consequences of COVID-19 on domestic violence. J Clin Nurs 2020; 29(13-14):2047-2049.

13. Wagers S. Domestic violence growing in wake of coronavirus outbreak. The Conversation 2020; 1(3):42-49.

14. Ornell F, Schuch JB, Sordi AO, Kessler FHP. "Pandemic fear" and COVID-19: mental health burden and strategies. Braz J Psychiatry 2020; 42(3):232-235.
15. Schmidt B, Crepaldi MA, Bolze SDA, Neiva-Silva L, Demenech LM. Saúde mental e intervenções psicológicas diante da pandemia do novo coronavírus (COVID-19). Estud Psicol 2020; 37:e200063.

16. Polanczyk GV. O custo da pandemia sobre a saúde mental de crianças e adolescentes [Internet]. Jornal da USP; 2020 [acessado 2020 out 12]. Disponível em: https://jornal.usp.br/artigos/o-custo-da-pandemiasobre-a-saude-mental-de-criancas-e-adolescentes/.

17. Brasil. Ministério da Saúde (MS). Conselho Nacional de Saúde (CNS). Resolução CNS no 510, de 7 de abril de 2016. Dispõe sobre as normas aplicáveis a pesquisas em Ciências Humanas e Sociais cujos procedimentos metodológicos envolvam a utilização de dados diretamente obtidos com os participantes ou de informações identificáveis ou que possam acarretar riscos maiores do que os existentes na vida cotidiana. Diário Oficial da União; 2016.

18. Denzin NK, Lincoln YS. Introdução: a disciplina e a prática da pesquisa qualitativa. In: Denzin NK, Lincoln YS, organizadores. O planejamento da pesquisa qualitativa: teorias e abordagens. $2^{\mathrm{a}}$ ed. Porto Alegre: Artmed; 2006. p. 15-41.

19. Poupart J, Deslauriers J, Groulx L, Laperrière A, Mayer R, Pires Á. A pesquisa qualitativa: enfoques epistemológicos e metodológicos. Petrópolis: Vozes; 2012.

20. Brasil. Lei $n^{\circ} 13.982$, de 2 de abril de 2020. Medida excepcional (auxílio emergencial) de proteção social de enfrentamento da emergência de saúde pública decorrente do coronavírus (Covid-19). Diário Oficial da União 2020; 2 abr.

21. Vinuto J. A amostragem em bola de neve na pesquisa qualitativa: um debate em aberto. Tematicas 2014; (22) 44:203-220

22. Aiello-Vaisberg TMJ, Ambrosio FF. O ser e o fazer: enquadres na clínica Winnicottiana. Mudancas Psicol Saude 2004; 2(13):343-363.

23. Tardivo LSLPC. $O$ adolescente e sofrimento emocional nos dias de hoje. São Paulo: Vetor; 2007.

24. Trinca W, organizador. Procedimento de Desenhos-Estórias: formas derivadas, desenvolvimentos e expansões. São Paulo: Vetor; 2013.

25. Winnicott DW. Jogo do rabisco. In: Winnicott C, organizador. Explorações psicanalíticas. Porto Alegre: Artes Médicas; 1994.

26. Aiello-Vaisberg TMJ. O uso de procedimentos projetivos na pesquisa de representações sociais: projeção e transicionalidade. Psicol USP 1995; 2(6):103-127.

27. Trinca AMT. Desenvolvimentos do Procedimento de Desenhos-Estórias. In: Trinca W, organizador. Procedimento de Desenhos-Estórias: formas derivadas, desenvolvimentos e expansões. São Paulo: Vetor; 2013. p. 27-76.

28. Aiello-Vaisberg TMJ, Ambrosio FF. Rabiscando Desenhos-Estórias com Tema: pesquisa psicanalítica de imaginários coletivos. In: Trinca W, organizador. Procedimento de Desenhos-Estórias: formas derivadas, desenvolvimentos e expansões. São Paulo: Vetor; 2013. p. 277-302. 
29. Tardivo LSLPC. Derivações do Procedimento de Desenhos-Estórias: atendimentos em grupo. In: Trinca W, organizador. Procedimento de Desenhos-Estórias: formas derivadas, desenvolvimentos e expansões. São Paulo: Vetor; 2013. p. 339-364.

30. Bardin L. Análise de conteúdo. Lisboa: Edições 70; 2011.

31. Instituto Brasileiro de Geografia e Estatística (IBGE). Pesquisa nacional por amostra de domicílios contínua - PNAD Contínua [Internet]. Rio de Janeiro: IBGE; 2020 [acessado 2020 abr 12]. Disponível em: https://www.ibge.gov.br/estatisticas/sociais/educacao/ 9171-pesquisanacional-por-amostra-de-domicilioscontinua-mensal.html?edicao $=19757 \& \mathrm{t}=$ destaques.

32. Winnicott DW. O ambiente e os processos de maturação: estudos sobre a teoria do desenvolvimento emocional. $2^{\mathrm{a}}$ ed. Porto Alegre: Artmed; 1983.

33. Ghilardi D, Bortolatto AF. Fraternidade nas relações $f a-$ miliares: a importância do resgate pós pandemia [Internet]. Editora Asces; 2020 [acessado 2020 out 20]. Disponível em: http://200-98-146-54.clouduol.com.br/ bitstream/123456789/2604/3/978-65-88213-03-2\%20 \%20359-369.pdf.

34. Ladeia DN, Silva AF, Gonçalves BBS, Damasceno CMC, Vieira JPG, Silva JAL, Lopes LMM, Queiroz NO, Lopes AG. Análise da saúde mental na população geral durante a pandemia de Covid-19. Rev Eletr Acervo Saude 2020; 46:e3925.

35. Brasil. Lei no 13.979, de 6 de fevereiro de 2020. Medidas para enfrentamento da emergência de saúde pública. Diário Oficial da União; 2020.

36. Souza-Junior JR, Cruz RCR, Cardoso-Brito V, Santos ELS, Fontes-Dutra M, Freitas IM, Pereira AG, Costa GB, Almeida-Junior S, Maniglia FP. COVID-19 e a promoção da saúde em tempos de pandemia. Rev Eletr Acervo Saude 2020; 46:e3837.

37. Dias EO. Família e amadurecimento: do colo à democracia. Rev Natur Hum 2017; 2(19):144-162.

38. Winnicott DW. A família e o desenvolvimento individual. $4^{\mathrm{a}}$ ed. São Paulo: Martins Fontes; 2018.

39. Giumelli RD, Santos MCP. Convivência com animais de estimação: um estudo fenomenológico. Rev Abordagem Gestalt 2016; 22(1):49-58.

40. Winnicott DW. A criança e seu mundo. $6^{\mathrm{a}}$ ed. Rio de Janeiro: LTC; 2019.

41. Rodrigues JVS, Lins ACAA. Possíveis impactos causados pela pandemia COVID-19 na saúde mental das crianças e o papel dos pais neste cenário. Pesqu Soc Desenvol 2020; 9(8):1-9.

42. Thomazini MG, Goulart EE. Relações familiares: a influência do virtual. Interacoes 2018; 48:49-64.

43. Pinchak C. Pandemia de coronavírus (COVID-19); surpresa, medo e bom manejo da incerteza na família. Arch Pediatr Urug.2020; 91(2):76-77.

44. Bittencourt RN. Pandemia, isolamento social e colapso global. Rev Esp Acad 2020; 19(221):168-178.

45. Jaime PC. Pandemia de COVID19: implicações para (in)segurança alimentar e nutricional [editorial]. Cien Saude Colet 2020; 25(7):2504.
46. Viero MG, Blümke AC. A sociabilidade exercida em torno do comer: um estudo entre universitários. Demetra 2016; 11(4):865-878.

47. Lima SO, Silva MA, Santos MLD, Moura AMM, Sales LGD, Menezes LHS, Nascimento GHB, Oliveira CCC, Reis FP, Jesus CVF. Impactos no comportamento e na saúde mental de grupos vulneráveis em época de enfrentamento da infecção COVID-19: revisão narrativa. Rev Eletr Acervo Saude 2020; 46:1-8.

48. Guidetti AA. Desempenho escolar e percepção infantil da motivação e suporte familiar [tese]. Campinas: Universidade Estadual de Campinas; 2013.

49. Dutra-Thomé L, Jesus MC, Santos LMG, Tanajura JLB, Gomes-Silvestre P, Santos RJ, Carvalho MP. Dicas de como conduzir seus projetos de vida em tempos de mudanças. Salvador: LAPROA-UFBA; 2020.
Artigo apresentado em 12/01/2021

Aprovado em 05/11/2021

Versão final apresentada em 07/11/2021

Editores-chefes: Romeu Gomes, Antônio Augusto Moura da Silva 
